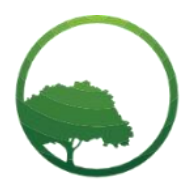

Research in Business \& Social Science

IJRBS VOL 10 NO 5 ISSN: 2147-4478

\title{
Does online ideal self-matter? Consumer perceptions of online brand advertisement
}

\author{
(DiD Aimee Peta Waterson ${ }^{(a)}$ (iD) Lebogang Mototo ${ }^{(b)}$ (D) Tinashe Chuchu ${ }^{(c)^{*}}$ \\ (a) School of Business Sciences, University of the Witwatersrand, No: 1, Jan Smuts Ave, Braamfontein, Johannesburg, 2000, South Africa. \\ ${ }^{(b)}$ Lecturer, School of Management Studies, Section of Marketing, University of Cape Town, Rondebosch, Cape Town, 7700, South Africa.

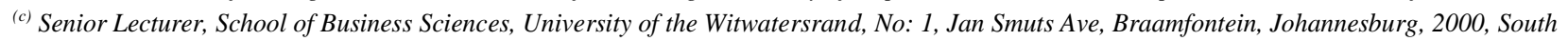 \\ Africa.
}

\author{
A R T ICLE INFO

\section{Article history:} \\ Received 10 July 2021 \\ Received in rev. form 27 July 2021 \\ Accepted 29 July 2021 \\ Keywords: \\ Online, Ideal Self, Brand Attitude, \\ Attachment, Consumers, Purchase \\ Intention \\ JEL Classification: \\ M310
}

\begin{abstract}
A B S T R A C T
The internet and online space have created numerous platforms for users to communicate and interact, where each platform provides access to different sources of information. The purpose of the study was to investigate online ideal self and its influence on brand attitude and attachment towards consumer purchase intention. A unique conceptual model was developed to test proposed hypotheses of the study. Social media is one of the leading communication platforms that have emerged in the online space. Social media allows consumers and brands to interact in an informal manner from anywhere in the world. The study adopted a quantitative approach utilising the survey method. Data was collected from 300 consumers. The data was then processed in SPSS 24 for descriptive statistics and AMOS 24 for hypotheses testing. A key finding suggests that social media consumers' attachment is considerably dependent on their attitudes towards those brands. Brands can use social media to receive real-time feedback from customers as well as track this feedback. Implications emerged from the findings and further research direction is proposed.
\end{abstract}

(c) 2021 by the authors. Licensee SSBFNET, Istanbul, Turkey. This article is an open access article distributed under the terms and conditions of the Creative Commons Attribution (CC BY) license (http://creativecommons.org/licenses/by/4.0/).

\section{Introduction}

The advancement of digital marketing platforms and user dynamics have significantly impacted how consumer-brand engagement is created, enriched and maintained (Barreto \& Ramalho, 2019; Peltier, Dahl \& VanderShee, 2020). The purpose of this research was to investigate online ideal self and its influence on brand attitude and attachment towards consumer purchase intention. This research was motivated by the interest in online advertising of brands that has intrigued marketers over the years (Bleier \& Eisenbeiss, 2015; Graham \& Wilder, 2020; Kim, 2018; Liu-Thompkins, 2019). Prior recent similar research (Fastoso \& González-Jiménez, 2020; Martinez, Rochford, Boyatzis \& Rodriguez-Chaves, 2021; Shan, Jiang, Cui, Wang \& Ivzhenko, 2021) covered the consumer's self ideal but did not explore brand attitudes and attachments.

The present research under investigation expands from these study by not only addressing the identified gap but examining how the promotion and advertisement of brands online influences consumer purchase intention of those brand. This was a clear research gap identified. The internet and online space have changed how consumers interact and engage with brands (Strauss, Frost \& Ansary, 2009). The online space as is form of media that allows users to self-select their own experiences, and enables marketers the ability to bridge media, gain feedback, iterate their message, and collect relationships (Caddell \& Clare, 2013; Strauss et al., 2009). Thus, the online space is a new method for consumers to explore content and for marketers to connect with customers. The online space is a communication platform where individuals can easily access and share information and knowledge amongst each other. Subsequently, the online space has thus transformed the way in which individuals communicate, learn and live their lives (Wang, 2007). Brand exposure is no longer sufficient for brands; a brand must actively engage and interact with consumers in order to capture their attention (Wang, 2007). As consumers are regularly engaging in social media sites such as Facebook, Twitter, Instagram

* Corresponding author. ORCID ID: 0000-0001-7325-8932

(C) 2021 by the authors. Hosting by SSBFNET. Peer review under responsibility of Center for Strategic Studies in Business and Finance. https://doi.org/10.20525/ijrbs.v10i5.1258 
and Myspace, blogs such as The HubSpot, and applications such as LinkedIn and YouTube, their tastes and preferences can be easily discerned by what they engage with in this online space (Sook Kwon, Kim, Sung \& Yun Yoo, 2014).

The present study's research problem is centered on the need to comprehend how online self-ideal influences a consumer's attitude toward brands and their attachment to those brands and how their eventually purchase brands advertised online. Social media sites and applications have provided a platform for brands to communicate with consumers on a virtual level and created an opportunity for them to track consumer behaviour through posts (Luczak \& Younkin, 2012). In order for brands to guarantee that their message reaches the desired consumers, they need to adapt their communication methods to meet the needs of their online consumers and ensure that brand equity is achieved (Folse, Burton, \& Netemeyer, 2013). However, online consumer behaviour is dynamic and can be difficult to predict due to the vast number of individual consumer differences that influence online behaviour (Gaile-Sarkane, 2008). These differences include elements such as personality, lifestyles, psychographics and individual motivations (Gaile-Sarkane, 2008). Customers tend to appreciate services that provide them with convenience (Mgxaji, Chinomona \& Chuchu, 2016). A consumer's personality reflects their consistent response to their environment and how they handle and react to social influence, persuasion and behaviours, which directly relates to their consumer's purchase behaviour intentions (Gaile-Sarkane, 2008). Therefore, it is important for brands to examine online social influences, provided by social media platforms, and adapt their communication methods to reach individual online personalities. Considering the above, it can be said that reaching the desired consumer has become increasingly difficult.

Social media applications, such as Facebook, previously allowed for direct advertising via individual profiles to target consumers or consumer groups. Recently, however, consumers have become increasingly motivated by their need to express their individual identity, to build relationships and obtain self-fulfilment (Moynagh \& Worsley, 2006), and thus are using these social media applications as a platform to openly express their views and opinions. This has enabled consumers to create and publicly display their ideal selves. These ideal selves are referred to as the individual's online persona, which resembles an individual's digital unconscious structuring of a digitally divided self (de Kerckhove \& de Almeida 2013). An individual's online persona has personal, social, institutional, legal, scientific and technological aspects that have to be reconsidered to allow for new ways of understanding and managing consumer identity (de Kerckhove \& de Almeida, 2013). According to de Kerckhove and de Almeida (2013), the internet is another part of computer culture that has advanced the comprehension of identity as multiplicity, on it, users are able to build a self by cycling through many selves.

In addition to the above, consumers are driven by the desire to make a statement about themselves in relation to others; individuals create their identities based on how they consume (Moynagh \& Worsley 2006). Consumers make statements not only about who they are, but about who they aspire to be, through their appearance, homes, cars and clothing (Gaile-Sarkane, 2008). Consumption is used by individuals to give a sense of belonging and affiliation with other consumers who make similar statements to their own. However, when examining social media interactions amongst recent consumers, there has been a certain level of scepticism regarding the validity and sincerity of messages transmitted via the internet (Way \& Austin, 2012). Many online personas are misrepresentations of the consumer's true self and thus make achieving brand equity very difficult for brands, as they struggle to positively influence consumer purchase behaviour. These consumers are using online personas as a mask for who they desire to be over whom they truly are (their actual personas). In other words, the 'digital you' is depicted to behave in a manner that is different to the 'real you'. Consequently, this study will explore the concept of online persona and the ideal self and question whether this ideal self has an influence on consumer purchase intention.

\section{Literature Review}

\section{Theoretical and Conceptual Framework}

\section{The Online Space and Social Media}

Due to the manner in which the online space has changed communication and interaction amongst individuals on a day-to-day basis, it has also considerably improved and eased the methods in which business is conducted, as organisations no longer require face-toface contact to trade and communicate (Wang, 2007). For example; online stock exchanges and social applications such as skype have allowed for business to be conducted virtually without direct contact. One of the most influential developments of the online space is that of social media. Social media is a term used to describe the online applications and sites which employ mobile and webbased technologies to create highly interactive channels through which individuals and communities communicate, share, discuss, and modify user-generated content (Kietzmann, Hermkens, McCarthy \& Silvestre, 2011). Social media is primarily an internet and mobile based tool (Luczak \& Younkin, 2012). An industry report by Nielsen (2011) depicts the degree to which social media platforms have subjectified the attitudes, beliefs and behaviours of consumers. It has been found that, within a sample of 10 global markets, social networks and blogs are the most frequently visited online platforms in various countries, as they received the most usage time by at least $60 \%$ of active Internet users (Vernuccio, 2014). Social media is therefore an essential tool not only for social interaction but for the conduct and communication of business as well. Consumers utilise social media for consumption and exposure to advertising. Thus the integration of online media and consumers has amplified advertising effectiveness (Wang, 2007).

Social media and the internet have thus satisfied the consumer's desire to actively communicate and interact with "real people", rather than the passive consumption of traditional marketing and advertising messages (Way \& Austin, 2012). This has led to more 
interactive consumer-to-consumer marketing (C2C), where consumers can use social media platforms to review what their friends/followers are interested in and what brands they use. In addition, consumers can see what their friends/ followers thoughts are, regarding those brands. However, the nature of these "friends" is not consistently sincere, and is often other social media users whom the individual has never met in person. The individual is also developing these friendships based on the respective personas that are being presented online (Way \& Austin, 2012). Thus, many friendships are being created using faux-personalities, known as online persona, that may not be a true representation of that specific user (Way \& Austin, 2012).

\section{Online Persona or Ideal Self}

Online persona, or Ideal Self, are generally interchangeable terms, and will be used here to refer to a set of claims made online by an individual about themselves or another individual, which they consider to be true (de Kerckhove \& de Almeida, 2013). These claims make up the desired personality, lifestyle as well as beliefs, which that individual wishes to portray as their own (Edelman \& Brandi, 2015). Online persona sanctions for individuals to create a separate identity, which may or may not reflect their true identity, but rather who they desire to be. de Kerckhove and de Almeida (2013) put forward identity as "an interactive social process of negotiation between the individual and society". Previous literature has researched the concept of a digital persona. Way and Austin (2012) conducted research on the "E-persona" with regard to building online communication and "E-friendships". Their study focussed on how college students use the online world as a medium for communication, and thus create e-personas to further develop themselves. Way and Austin (2012) provide an understanding on how online friendships may be based on faux-personalities and lifestyles, and how these friendships influence other online consumers in their attitudes towards brand preferences.

\section{Actual Persona}

Individual actual persona will be discussed here in contrast to the individual ideal persona. Actual persona, or actual self, refers to how a consumer actually sees themselves in relation to who they are in real-life (Malär, Krohmer, Hoyer \& Nyffenegger, 2011). It includes all aspects of the person, such as their true personality, appearance, habits, behaviours and opinions (Malär et al., 2011). Actual persona is thus an authentic image or brand, which an individual has created for themselves, and represents their everyday life (Way \& Austin, 2012). Malär et al. (2011) provides understanding on the effects of self-congruence on users emotional brand attachment. The authors reviewed the relationship between the fit of the brand's personality with the consumer's actual self versus their ideal self.

\section{Brand Attitude}

In relation to the consumer actual and ideal persona, it is important to understand how these relative personae have different perceived brand attitudes. Consumers seek exclusivity and luxury from brands (Maziriri \& Madinga, 2018), which likely influences their attitudes toward brands. Brand attitude is a brand's evaluation, made by consumers, based on their individual reactions to both the favourable and unfavourable brand information supplied to them (Folse et al., 2013; Fishbein \& Ajzen, 1975; Murphy \& Zajonc, 1993). Understanding customer attitudes is essential for the success of any organisation (Mashele \& Chuchu, 2018). Thus, a consumer's actual persona will not necessarily respond to brand exposure in the same manner as their ideal persona is perceived to brand attitude is considered academically to be one of the key aspects underwriting a brands overall equity (Park, MacInnis, Priester, Eisingerich \& Iacobucci, 2010). Brand Attitude can further be extended to include the aspect of brand trust, a term which refers to how consumers perceive the reliability of the brand and what obligations the consumer expects to be fulfilled when consuming the brand (Folse et al., 2013). Consumer brand attitude is hence an important aspect for brands to evaluate when targeting their consumers, and deciding whether ideal persona should be targeted in order to influence the consumer purchase behaviour.

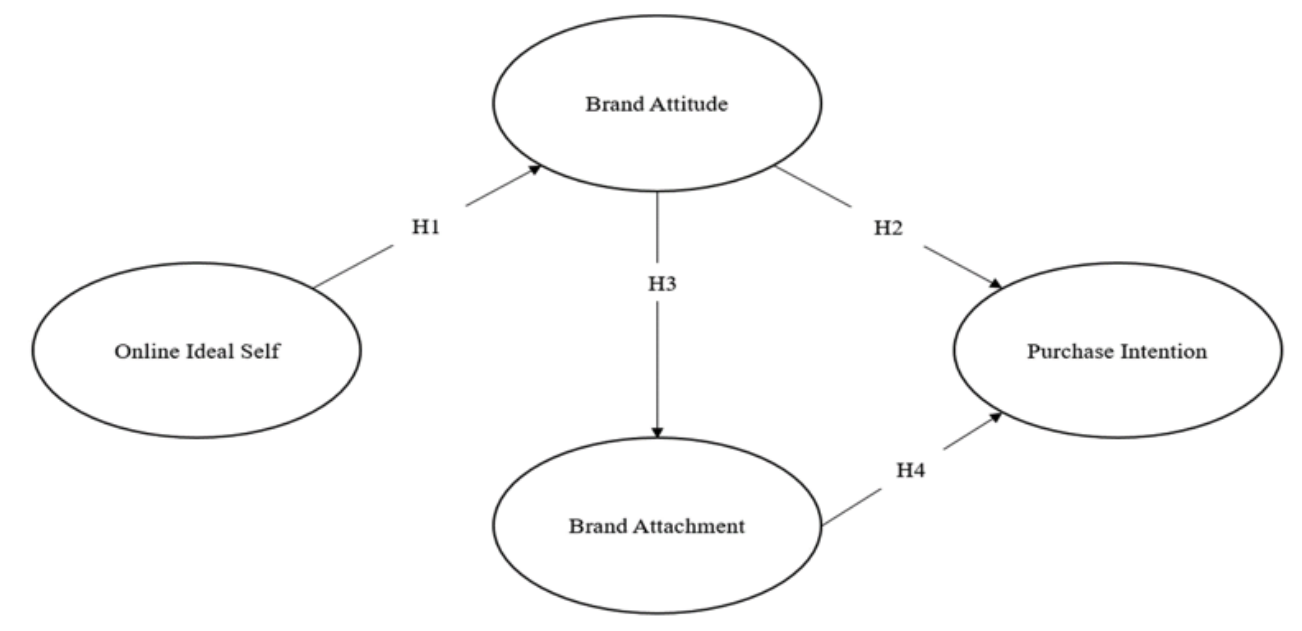

Figure 1: Conceptual Research Model 


\section{Hypotheses Statements}

H1: Online ideal self has a positive influence on brand attitude.

$\mathrm{H} 2$ : Brand attitude has a positive influence on purchase intention.

H3: Brand attitude has a positive influence on brand attachment.

$\mathrm{H} 4$ : Brand attachment has a positive influence on purchase intention.

This section presented the proposed hypotheses for the research based on the literature. The following section outlines the research methodology used for the study.

\section{Research and Methodology}

The research was quantitative in nature adopting the survey method. Due to the absence of a sampling frame, convenience sampling a form of non-probability sampling was used to determine suitable respondents. This was a result of working with an unknown population. The measurement instrument comprised of demographic questions and Likert-scale questions. A unique conceptual model was developed to test the proposed hypotheses of study. This conceptual model is presented in figure 1 and Likert scales are used for measuring each construct. The Likert-scale questions are based on four constructs, namely; online ideal self, brand attitude, brand attachment and purchase intention. The profile of respondents was built around social media consumption of brands. The data collection process resulted in 300 questionnaires being returned from the 336 questionnaires that were distributed. The returned questionnaires were processed in SPSS 24 for descriptive statistics and AMOS 24 for hypotheses testing. Proposed hypotheses are tested through structural equation modeling. Structural equation modeling is conducted following a two-part procedure starting with confirmatory factor analysis followed by hypotheses testing. The four hypotheses were tested to measure and causality and effect of components of the model. The following section presents the findings of the research.

\section{Results and Discussion}

The findings of the study are presented in this section. The respondent profile is presented together with all other demographic data of the research. This is then followed by inferential statistics which were generated through structural equation modeling. Structural equation modeling was conducted through two processes, confirmatory factor analysis followed by hypotheses testing. Below is table 1 , an illustration of the respondent profile.

Table 1: Respondent Profile

\begin{tabular}{ll}
\hline Gender & Frequency \\
\hline Female & $64 \%$ \\
\hline Male & $36 \%$ \\
\hline Total & $\mathbf{1 0 0 \%}$ \\
\hline Age & \\
\hline $\mathbf{1 8}$ to 29 years & $89 \%$ \\
\hline 30 years and older & $11 \%$ \\
\hline Total & $\mathbf{1 0 0 \%}$ \\
\hline Status of Respondent & \\
\hline Student & $68 \%$ \\
\hline Non-student & $32 \%$ \\
\hline Total & $\mathbf{1 0 0 \%}$ \\
\hline Active on Social Media & \\
\hline Yes & \\
\hline No & $99 \%$ \\
\hline Total & $1 \%$ \\
\hline
\end{tabular}

Table 1 above presents the respondent profile were gender, age, status and social media activeness of the respondent is presented. This is the first part of the study's descriptive statistics. Females had a higher representation in the study, accounting for almost double. In terms of age, 18 to 29 year olds accounted for more than $20 \%$ of the sample while the remainder indicated that they were at least 30 years and older. The majority of the participants were students, representing $68 \%$ of the sample. Almost all participants confirmed that they were active social media users. The following sections present the second part of the descriptive statistics where 
detailed analysis of respondents' social media activity is illustrated. Figure 2, below presents the respondents' preferred device for accessing social media.

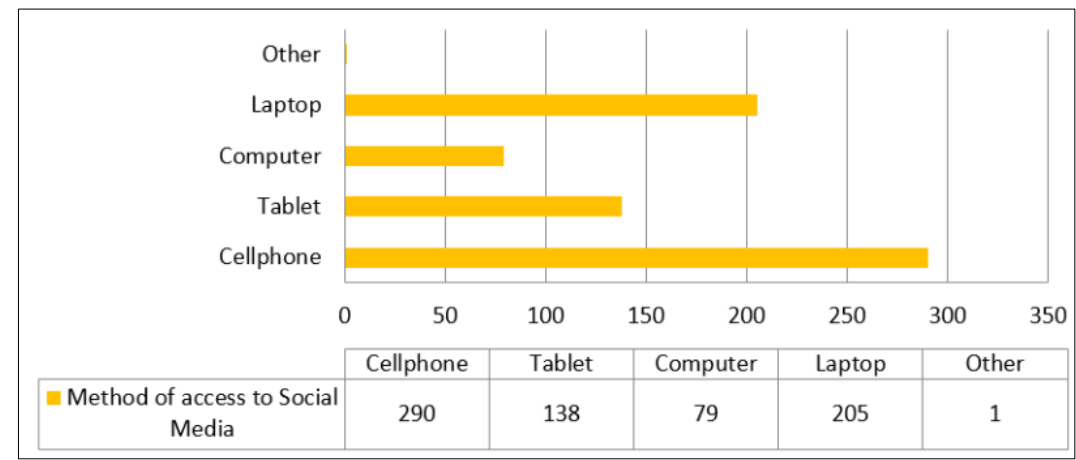

Figure 2: Device used to Access Social Media

Figure 2 above presents the devices used by participants to access social media. It can be observed that respondents acknowledge using more than one device to access social media with an overwhelming majority stating that they use their cellphones to access social media. Cellphones were used $97 \%$ while tablets accounted for $46 \%$ of the sample and desktop computers (26\%). Laptops were used by $68 \%$ ) and other devices only accounted for $(0.3 \%)$ of the sample. The remaining $1 \%$ of overall respondents did not engage in social media. The social media platforms most frequented by the respondents are present in figure 3 which follows.

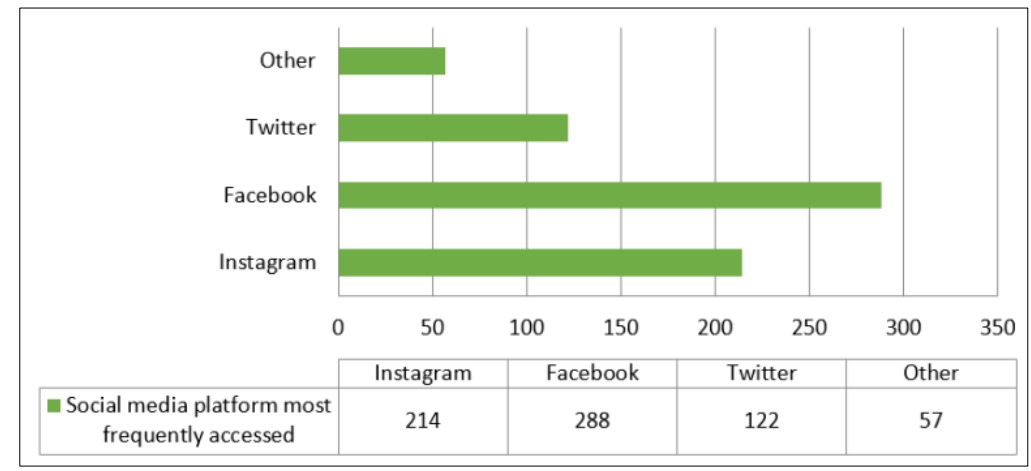

Figure 3: Social Media Platform Accessed

Figure 3 above presents the most frequented social media platforms which Facebook having the most users at $96 \%$. It should be noted that respondents selected more than one social media platform. The second most represented platform was Instagram (71\%) followed by Twitter (42\%) and the "other" platforms accounting for the remainder. Figure 4 in the following section illustrates duration of respondents' active participation on the various social media platforms.

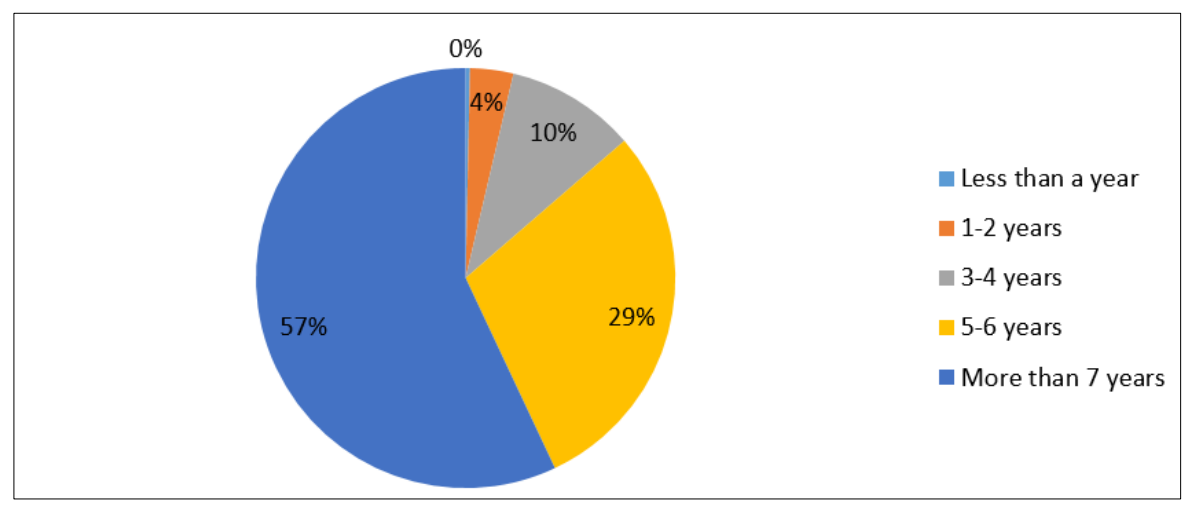

Figure 4: Length of Active Membership on Social Media Platforms 
It can be observed in figure 4 above that $89 \%$ of these social media users browse these applications every day. However, only $11 \%$ post to social media every day. Majority of applicants, $44 \%$, spent 1-2 hours browsing social media every day, with $24 \%$ spending 3-4 hours and 23\% spending less than an hour. This equates to the majority of social media users spending approximately $8-10 \%$ of their day browsing social media. The following chart, figure 5 presents the users' frequency of browsing on social media platforms.

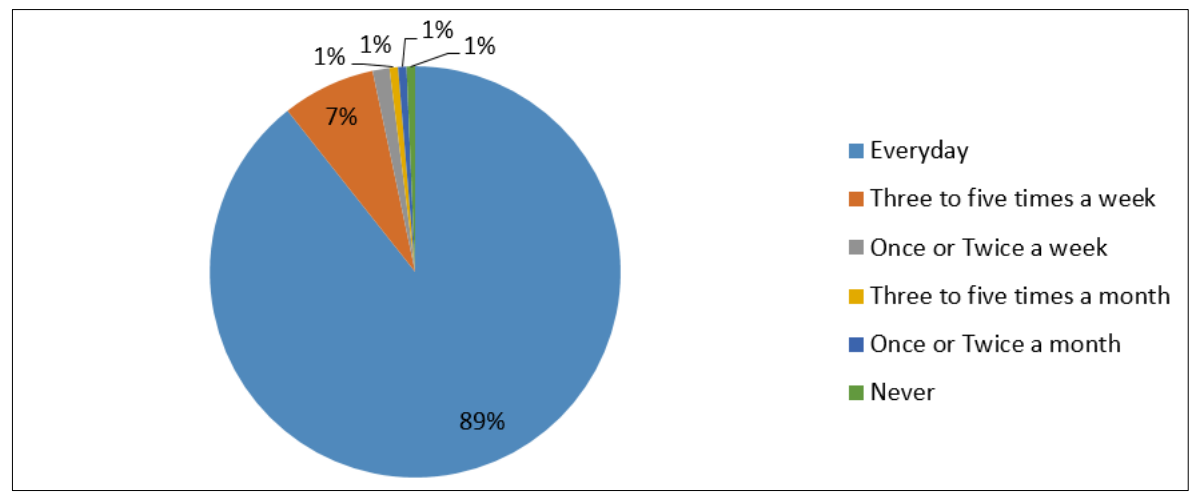

Figure 5: Frequency of Browsing on Social Media Platforms

Figure 5 above presents the frequency of browsing on social media platforms. It is clear from the evidence presented that most of the users browse social media platforms every day. This group of users is followed by those who browse at least three to five times a week. However, it is imperative to note that the difference between the most represented group and the second most represented group is significant as the former accounts for almost 90 percent and the later accounts for only $7 \%$. It can therefore be said that almost all users browse social media platforms on a daily basis. The section that follows illustrates the users' frequency of posting on social media platforms.

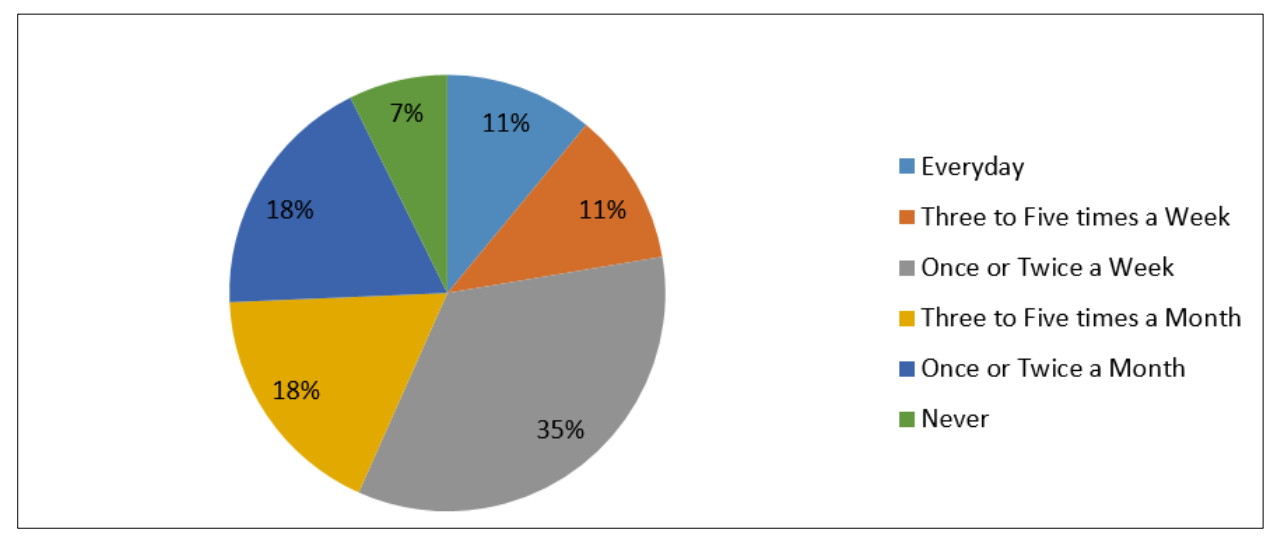

Figure 6: Frequency of Posting on Social Media Platforms

Figure 6 presents the frequency of positing on social media by users. It is observed that the largest group of users represented is that of users who post once or twice a week (35\%), followed by those who post once or twice a month and three to five times a month both at (18\%). The smallest group of users was that of users who never post as indicated by $7 \%$. It is interesting to note that when figure 5 and 6 are compared, the respondents show that they are very active on social media as consumers but they not very active as content creators (user who post on social media) themselves. This could provide useful insights to brand managers and marketers of brands. For example, social media users are more of content recipients than providers which means that they spend more time looking, reviewing and analysing brands and content posted by those brands than reading their own content. The following illustration presents figure 7, hours spent browsing social media platforms per day. 


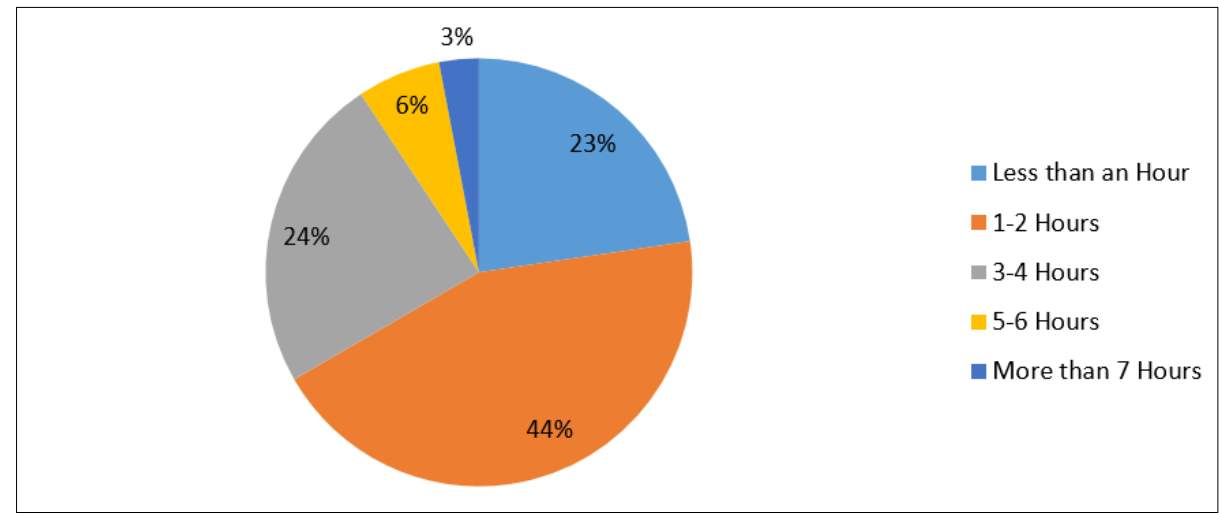

Figure 7: Hours spent Browsing Social Media Platforms per Day

Figure 7 illustrates the amount of time in hours spent by users browsing social media platforms per day. The largest group of users is that of those who browse at least one to 2 hours a day followed by those who browse for three to four hours per day. The smallest group of users are those who browse for less than an hour. The following illustration, figure 8 , presents the types of social media accounts most followed by users.

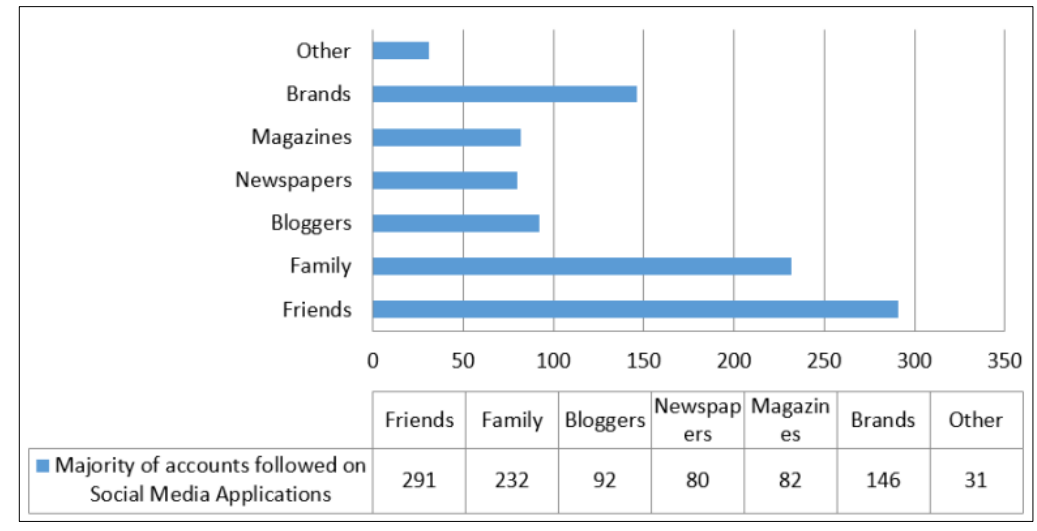

Figure 8: Types of Social Media Accounts followed by Users

Figure 8 presents the types of accounts followed by social media users. It is evident that most users follow their friends and families. The second most followed accounts are those of brands. This then shows that brands should always ensure that their online presence is as positive as possible and that existing customers as well as potential customers are always watching them. However, the downside of having such a strong following is that any negative publicity for the brands will be immediately known by a large audience, making damage control difficult, if not impossible. The following section explores the accuracy analysis statics followed by a discussion.

Table 2: Accuracy Analysis Statistics

\begin{tabular}{|c|c|c|c|c|c|c|c|c|c|c|c|}
\hline \multirow{2}{*}{\multicolumn{2}{|c|}{$\begin{array}{l}\text { Research } \\
\text { Construct }\end{array}$}} & \multicolumn{4}{|c|}{ Descriptive Statistics } & \multicolumn{2}{|c|}{$\begin{array}{l}\text { Cronbach's } \\
\text { Test }\end{array}$} & \multirow[t]{2}{*}{$\begin{array}{l}\text { C.R. } \\
\text { Value }\end{array}$} & \multirow[t]{2}{*}{$\begin{array}{l}\text { AVE } \\
\text { Value }\end{array}$} & & \multirow[t]{2}{*}{$\begin{array}{l}\text { Factor } \\
\text { Loading }\end{array}$} \\
\hline & & \multicolumn{2}{|c|}{ Mean Value } & \multicolumn{2}{|c|}{$\begin{array}{l}\text { Standard } \\
\text { Deviation }\end{array}$} & $\begin{array}{l}\text { Item- } \\
\text { total }\end{array}$ & $\begin{array}{l}\text { alpha } \\
\text { value }\end{array}$ & & & $\begin{array}{l}\text { Highest } \\
\text { Shared } \\
\text { Variance }\end{array}$ & \\
\hline \multirow[t]{3}{*}{ OIS } & OIS1 & 5,183 & \multirow[t]{3}{*}{5,424} & 1,375 & \multirow[t]{3}{*}{1,231} & 0,716 & \multirow[t]{3}{*}{0,822} & \multirow[t]{3}{*}{0,867} & \multirow[t]{3}{*}{0,809} & & 0,828 \\
\hline & OIS3 & 5,217 & & 1,247 & & 0,714 & & & & 0,006 & 0,825 \\
\hline & OIS5 & 5,873 & & 1,071 & & 0,625 & & & & & 0,828 \\
\hline \multirow[t]{5}{*}{ BTD } & BTD1 & 5,723 & \multirow[t]{5}{*}{5,532} & 1,412 & \multirow[t]{5}{*}{1,465} & 0,757 & \multirow[t]{5}{*}{0,913} & \multirow[t]{5}{*}{0,909} & \multirow[t]{5}{*}{0,783} & \multirow[t]{5}{*}{0,493} & 0,848 \\
\hline & BTD3 & 5,150 & & 1,522 & & 0,782 & & & & & 0,745 \\
\hline & BTD4 & 5,310 & & 1,521 & & 0,749 & & & & & 0,717 \\
\hline & BTD5 & 5,767 & & 1,395 & & 0,795 & & & & & 0,837 \\
\hline & BTD6 & 5,710 & & 1,474 & & 0,808 & & & & & 0,924 \\
\hline
\end{tabular}




\begin{tabular}{|c|c|c|c|c|c|c|c|c|c|c|c|}
\hline \multirow[t]{3}{*}{ BCH } & BCH1 & 5,527 & \multirow[t]{3}{*}{5,343} & 1,386 & \multirow[t]{3}{*}{1,365} & 0,728 & \multirow[t]{3}{*}{0,859} & \multirow[t]{3}{*}{0,857} & \multirow[t]{3}{*}{0,783} & \multirow[t]{3}{*}{0,493} & 0,827 \\
\hline & $\mathrm{BCH} 2$ & 5,353 & & 1,319 & & 0,755 & & & & & 0,844 \\
\hline & $\mathrm{BCH} 3$ & 5,150 & & 1,388 & & 0,720 & & & & & 0,776 \\
\hline \multirow[t]{5}{*}{ PI } & PI1 & 5,547 & \multirow[t]{5}{*}{5,296} & 1,422 & \multirow[t]{5}{*}{1,608} & 0,780 & \multirow[t]{5}{*}{0,906} & \multirow[t]{5}{*}{0,925} & \multirow[t]{5}{*}{0,812} & \multirow[t]{5}{*}{0,484} & 0,906 \\
\hline & PI2 & 5,430 & & 1,472 & & 0,871 & & & & & 0,92 \\
\hline & PI3 & 5,543 & & 1,429 & & 0,859 & & & & & 0,938 \\
\hline & PI4 & 5,310 & & 1,588 & & 0,871 & & & & & 0,858 \\
\hline & PI5 & 4,650 & & 2,130 & & 0,574 & & & & & 0,548 \\
\hline
\end{tabular}

Key: OIS: Online Ideal Self, BTD: Brand Attitude, BCH: Brand Attachment, PI: Purchase Intention, CR value: Composite Reliability value, AVE: Average Variance Extracted value

Table 2 above presents the accuracy analysis statistics of the research. It is observed that the data is normally distributed as the mean values are all within a close range while further evidence of normal distribution of data is evident through standard deviation values ranging from -2 to +2 . All item total values are above 0.50 showing that the data is reliable. Further data reliability was checked through the Cronbach's alpha which revealed that all values are above 0.7 necessary for confirming reliability as recommended by (Nunnally \& Bernstein, 1994). In addition, composite reliability values are above 0.6 necessary for reliability while average variance extracted values are above 0.5 establishing validity of the constructs. Comparing the average variance extracted and highest shared variance values, confirms the existence of discriminant validity. The factor loadings are all above 0.5 , establishing that all construct are reliable. It can be said without doubt that all constructs are both reliable and valid making them suitable for inferential statistics which will be explored later in the research through hypotheses testing. The next section presents table 3, model fit criteria followed by a discussion.

Table 3: Model fit Criteria

\begin{tabular}{lllllllll}
\hline Model Fit Criteria & CMIN/DF & GFI & NFI & RFI & TLI & IFI & CFI & RMSEA \\
\hline Indicator Value & 1.781 & 0.940 & 0.961 & 0.945 & 0.975 & 0.982 & 0.982 & 0.051
\end{tabular}

CFA Model: Confirmatory factor analysis model; CMIN/DF: Chi-square; GFI: Goodness of fit index; NFI: Normed Fit index; RFI; Relative Fit Index; IFI: Incremental Fit Index; TLI: Tucker Lewis Index; CFI: Comparative Fit Index. RMSEA: Root Measure Standard Error Approximation

Table 3 shows that all model fit criteria were met with GFI, NFI, RFI, TLI, IFI and CFI all reaching the required 0.9 with GF NFI, RLI, TLI, IFI and CFI reporting values of results were $0.961,0.945,0.982,0.975$ and 0.982 respectively. Chi-square was 1.781 falling below the recommended value of 3 , while the root measure standard error approximation was 0.051 falling below the required 0.06 further confirming model fit of the data. The following section illustrates the study's structural model in Figure 9 followed by a discussion.

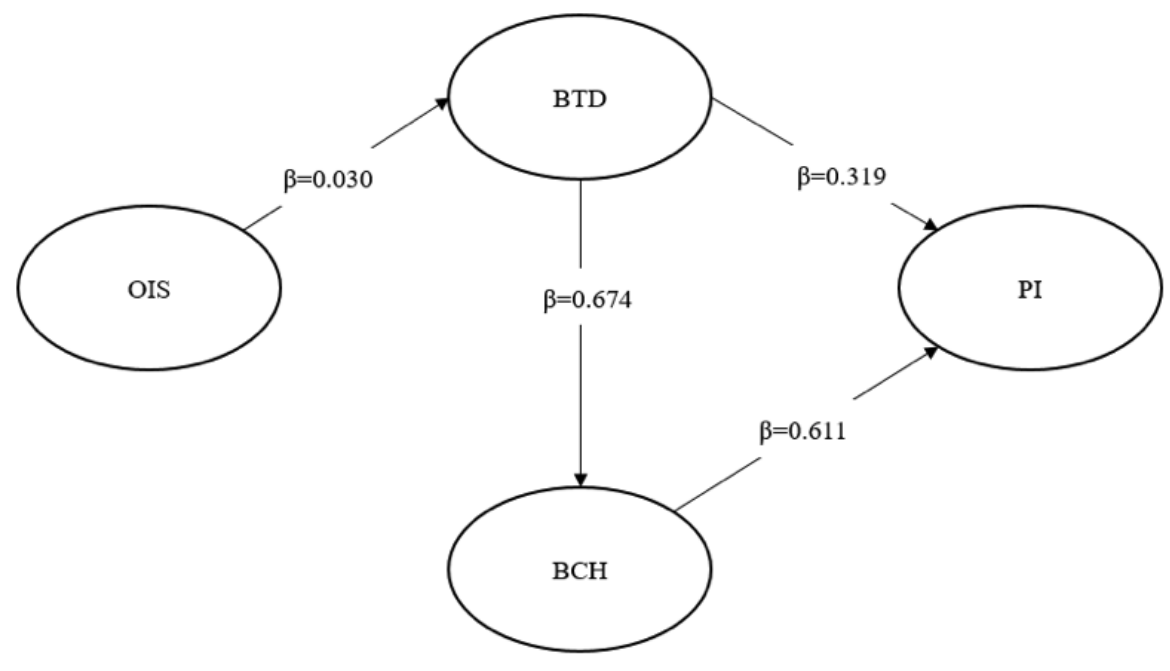

Figure 9: Structural Model

Key: OIS: Online Ideal Self, BTD: Brand Attitude, BCH: Brand Attachment, PI: Purchase Intention, P<0.01 level of significance.

Figure 9 illustrates the structural model for the study which is followed by the hypothesis results in table 4 depicting all tested hypotheses, their corresponding estimates, p-values and outcomes. 
Table 4: Hypothesis Results

\begin{tabular}{lcccl}
\hline Relationship & Hypothesis & Estimate & P-Value & Outcome \\
\hline OIS $\rightarrow$ BTD & H1 & 0.030 & 0.792 & $\begin{array}{l}\text { Supported but not } \\
\text { significant }\end{array}$ \\
\hline BTD $\rightarrow$ PI & H2 & 0.319 & $* * *$ & $\begin{array}{l}\text { Supported and } \\
\text { significant }\end{array}$ \\
\hline BTD $\rightarrow$ BCH & H3 & 0.674 & $* * *$ & $\begin{array}{l}\text { Supported and } \\
\text { significant }\end{array}$ \\
\hline BCH $\rightarrow$ PI & H4 & 0.611 & $* * *$ & $\begin{array}{l}\text { Supported and } \\
\text { significant }\end{array}$ \\
\hline
\end{tabular}

Key: OIS: Online Ideal Self, BTD: Brand Attitude, BCH: Brand Attachment, PI: Purchase Intention, $P<0.01$ level of significance.

In the table above, it can be observed that all hypotheses tested are supported and significant with the exception of one which is only supported but not significant. The first hypotheses, H1 (online ideal self and brand attachment) is found to be supported at an estimate of 0.030 but not significant at $\mathrm{p}<0.01$ with a $\mathrm{p}$-value higher of 0.792 , higher than the 0.01 required for significance. Such a finding suggests that even though online ideal self is related to brand attachment, the effect of this relationship does not play a notable role in the consumer's mind. This therefore implies that consumers' attachment to brands is loosely dependent on their online ideal self as this could easily change considering that the estimate for this relationship is considerably weak. In other words, it could be said that consumers' attachment to a brand based on online ideal self, fluctuates, sometimes this attachment happens and sometimes it does not. It is important to note that, of all the hypotheses tested, this is the weakest of them all. The following hypothesis tested, $\mathrm{H} 2$ (brand attitude and purchase intention). This hypothesis is found to be both supported and significant at $\mathrm{p}<0.01$ with a $\mathrm{p}$-value lower than 0.01 as indicated by the $* * *$ and an estimate of 0.319 . This finding suggests that brand attitudes are related to brand attachment. The more positive the consumers' brand attitudes are, the more the likelihood of them purchasing that brand. This result confirms that purchasing a brand followed online is dependent of the consumer's attitude toward that brand online or more specifically on social media.

The third hypotheses, H3 (brand attitude and brand attachment) is found to be both supported and significant at $p<0.01$ with a $p$ value lower than 0.01 as indicated by the $* * *$ and an estimate of 0.674 . This finding suggests that consumers' closely associate brand attitudes with their attachment. This means that consumers' attachment to brands is highly dependent on their attitudes toward that particular brand. This implies that the more the positive consumers' attitudes toward a brand are, the more their attachment to that brand would be. It is important to note that this hypothesis is the strongest of all the relationships tested. The last hypothesis, H4 (brand attachment and purchase intention) is found to be both supported and significant at $\mathrm{p}<0.01$ with a $\mathrm{p}$ value lower than 0.01 as indicated by the ${ }^{* * *}$ and an estimate of 0.611 .This finding suggests that consumers' willingness to purchase a brand is dependent on their attachment to that particular brand. In other words, the stronger the consumers' attachment to a brand is, the higher the likelihood of those consumers purchasing that brand. The following sections explore the academic and managerial implications emerging from the findings of the research.

\section{Implications}

Academically, the current study contributes to existing literature on the relationship between brand attitude, brand attachment and purchase intention of consumers. The implication of this relationship is that marketers need to understand the behaviour of consumers in order to predict consumers' online behaviour purchasing goods based on their attitudes and attachments to brands. This study also contributes academically to new literature on the online ideal self, and its influence on consumer brand attitudes, which are found to be positive. This implied that consumer attitudes towards purchasing brands are directly impacted by consumers' perceived personality traits within their online profiles, thus contributing to their purchase decisions. Therefore, managers of genuine brands have to be aware of the perceived differences between consumer's actual and online personas and make note of different purchasing patterns between the two.

The managerial implications of this study show relevance for marketing practitioners interested in understanding consumers' online ideal self. According to the findings, brand attitude is seen to have a strong influence on brand attachment, suggesting that marketers should create emotional attachments with consumers and brands through influencing their attitudes. Marketers need to further evaluate the many factors influencing consumer attitudes and examine the differences between the attitudes of the online ideal self versus the actual-self for effectiveness. Brand attachment is found to have the highest influence on consumer purchase intention ahead of brand attitude. This suggests that marketing to consumers to create emotional attachments is stronger than merely attempting to influence their brand attitudes. There was a positive yet weak relationship between the influence of the online ideal self and brand attitude. This implies that marketers should find ways of understanding consumer online ideal selves in order to observe their purchase 
behaviours, however marketing to these online ideal selves will require stronger attachments than actual selves as the online ideal self is subject to change attitude.

\section{Conclusions}

The purpose of the study was to investigate online ideal self and its influence on brand attitude and attachment toward consumer purchase intention. It explored the extent to which users' self-identity and their attitudes toward brands online would affect their attachment to the brand and eventual purchase intention. This was done through the development of a unique conceptual model employed to test proposed hypotheses relevant to the research at hand. It is observed that all relationships are supported and significant with the exception of a single relationship, which was not supported even regardless of being significant. This was the proposed hypothesis between online ideal self and brand attitude. Furthermore, the analysis revealed that this was also the weakest of all relationships. On the other hand, the strongest relationship is that of brand attitude and brand attachment suggesting that social media users' attitude towards brand. The following section discusses the research limitations and possible further research direction on the topic.

The current study leaves room for further future research on the subject of online ideal self and its influences. This study had limitations both from a practical point of view as well as from a conceptual point of view. Practically, the methodology could be changed in further research. The present study used the survey method adopting a closed ended questionnaire. This restricted the extent to which respondents could express themselves. It would therefore be recommend that a qualitative approach be used to assess consumers' online ideal self, brand attitude and attachment through in-depth interviews as this could reveal deeper insights on how these users actually feel about the subject. Findings from such qualitative studies will not exist in isolation as they can be used reflect on the present study. Similarities and differences can be reviewed to come-up with more rigorous discussions which ultimately lead to more substantial conclusions. Another issue is that, all respondents are from a single region. This could have led to the sampling of respondents with very similar traits and thinking thus introducing respondent bias into the study. Further research on the same topic and issues should have a more diverse sample both demographically and geographically as this will provide a more widespread range of responses making generalisation of findings more accurate.

Conceptually, the same model could be analysed in further research in a way that incorporates potential hypotheses that are not included in the present study. For example, a direct relationship could be tested between online ideal self and brand attachment. This would provide empirical evidence on how online ideal self and brand attachment are associated. Another potential hypothesis that could be tested is that of a direct relationship between online ideal self and purchase intention. This would reveal the extent to which online ideal self would impact likelihood of purchase intention without the influence of consumers' attitude toward the brand. Modifying the conceptual model should not be restricted to testing potential hypotheses that are not included in the current study but it should also involve deleting some hypotheses tested in the current research. For instance, removing the hypothesis between brand attitude and brand attachment could significantly affect how online ideal self affects brand attitude or even the entire model for that matter. Further discussion on the topic would benefit from additional constructs being included in the current conceptual model as this would continue the discussion on consumers' online purchase behaviour with new insights.

\section{References}

Ajzen, I., \& Fishbein, M. (1975). A Bayesian analysis of attribution processes. Psychological bulletin, 82(2), $261-277$. https://doi.org/10.1037/h0076477

Barreto, A. M., \& Ramalho, D. (2019). The impact of involvement on engagement with brand posts. Journal of Research in Interactive Marketing, 13(3), 277-301. https://doi.org/10.1108/JRIM-01-2018-0013

Bleier, A., \& Eisenbeiss, M. (2015). The importance of trust for personalized online advertising. Journal of Retailing, 91(3), 390409. https://doi.org/10.1016/j.jretai.2015.04.001

Caddell, L. S., \& Clare, L. (2013). Studying the self in people with dementia: How might we proceed? Dementia, 12(2), $192-209$. https://doi.org/10.1177/1471301211418486

de Kerckhove, D., \& de Almeida, C.M. (2013). What is a digital persona? Technoetic Arts: A Journal of Speculative Research, 11 (3), 277-87. https://doi.org/10.1386/tear.11.3.277_1

Edelman, B., \& Brandi, W. (2015). Risk, information, and incentives in online affiliate marketing. Journal of Marketing Research, 52(1), 1-12. https://doi.org/10.1509/jmr.13.0472

Fastoso, F., \& González-Jiménez, H. (2020). Materialism, cosmopolitanism, and emotional brand attachment: The roles of ideal selfcongruity and perceived brand globalness. Journal of Business Research, 121, 429-437. https://doi.org/10.1016/j.jbusres.2018.12.015

Folse, J. A. G., Burton, S., \& Netemeyer, R. G. (2013). Defending brands: Effects of alignment of spokes character personality traits and corporate transgressions on brand trust and attitudes. Journal of Advertising,42(4), 331-342. https://doi.org/10.1080/00913367.2013.795124

Gaile-Sarkane, E. (2008). What Does the E-Customer Really Wants?. Economics \& Management, 13, 256-60. 
Graham, K. W., \& Wilder, K. M. (2020). Consumer-brand identity and online advertising message elaboration: effect on attitudes, purchase intent and willingness to share. Journal of Research in Interactive Marketing, 14 (1), 111-132. https://doi.org/10.1108/JRIM-01-2019-0011

Kietzmann, J. H., Hermkens, K., McCarthy, I. P., \& Silvestre, B. S. (2011). Social media? Get serious! Understanding the functional building blocks of social media. Business horizons, 54(3), 241-251. https://doi.org/10.1016/j.bushor.2011.01.005

Kim, N. Y. (2018). The effect of advertising content control on advertising effectiveness in the different forced exposure circumstance. Journal of Promotion Management, 24(6), 845-862. https://doi.org/10.1080/10496491.2017.1408528

Liu-Thompkins, Y. (2019). A decade of online advertising research: What we learned and what we need to know. Journal of advertising, 48(1), 1-13. https://doi.org/10.1080/00913367.2018.1556138

Luczak, C., \& Younkin, N. (2012). Net generation: A conceptual framework of the consumer socialization process. Academy of Marketing Studies Journal, 16(2), 47-51.

Malär, L., Krohmer, H., Hoyer, W. D., \& Nyffenegger, B. (2011). Emotional brand attachment and brand personality: The relative importance of the actual and the ideal self. Journal of marketing, 75(4), 35-52. https://doi.org/10.1509/jmkg.75.4.35

Mashele, F., \& Chuchu, T. (2018). An Empirical Investigation into the Relationship between Sustainability and Supply Chain Compliance within the South African public and the private sector. Journal of Business \& Retail Management Research, 12(2), 121-132.https://doi.org/10.24052/JBRMR/V12IS02/AEIITRBSASCCWTSAPATPS

Martinez, H. A., Rochford, K., Boyatzis, R. E., \& Rodriguez-Chaves, S. (2021). Inspired and Effective: The Role of the Ideal Self in Employee Engagement, Well-Being, and Positive Organizational Behaviors. Frontiers in Psychology, 12, 1-12. https://doi.org/10.3389/fpsyg.2021.662386

Maziriri, E. T., \& Madinga, N. W. (2018). Data to model the prognosticators of luxury consumption: A partial least squares-structural equation modelling approach (PLS-SEM). Data in brief, 21, 753-757. https://doi.org/10.1016/j.dib.2018.10.032

Mgxaji, B., Chinomona, R., \& Chuchu, T. (2016). The Predictors of Business Performance in the Investment Management Industry. Journal of Global Business \& Technology, 12(2), 56-69.

Moynagh, M., \& Worsley, R. (2006). Tomorrow's consumer-the shifting balance of power. Journal of Consumer Behaviour: An International Research Review, 1(3), 293-301. https://doi.org/10.1002/cb.74

Murphy, S. T., \& Zajonc, R. B. (1993). Affect, cognition, and awareness: affective priming with optimal and suboptimal stimulus exposures. Journal of personality and social psychology, 64(5), 723-739. https://doi.org/10.1037/0022-3514.64.5.723

Nielsen (2011). State of Social Media: The Social Media Report Q3. Retrieved from https://www.nielsen.com/wpcontent/uploads/sites/3/2019/04/nielsen-social-media-report.pdf Accessed 21/06/2021

Nunnally, J. C., \& Bernstein, I. H. (1994). Psychological theory. New York, NY: MacGraw-Hill, 131-147.

Park, C. W., MacInnis, D. J., Priester, J., Eisingerich, A. B., \& Iacobucci, D. (2010). Brand attachment and brand attitude strength: Conceptual and empirical differentiation of two critical brand equity drivers. Journal of marketing, 74(6), 1-17. https://doi.org/10.1509/jmkg.74.6.1

Peltier, J., Dahl, A. J., \& VanderShee, B. A. (2020). Antecedent consumer factors, consequential branding outcomes and measures of online consumer engagement: current research and future directions. Journal of Research in Interactive Marketing, 14(2), 239-268.https://doi.org/10.1108/JRIM-01-2020-0010

Shan, J., Jiang, L., Cui, A. P., Wang, Y., \& Ivzhenko, Y. (2021). How and when actual-ideal self-discrepancy leads to counterfeit luxury purchase intention: a moderated mediation model. International Journal of Consumer Studies, 00, 1-13. https://doi.org/10.1111/ijcs.12730

Sook Kwon, E., Kim, E., Sung, Y., \& Yun Yoo, C. (2014). Brand followers: Consumer motivation and attitude towards brand communications on Twitter. International Journal of Advertising, 33(4), 657-680. https://doi.org/10.2501/IJA-33-4-657-680

Strauss, J., Frost, R., \& Ansary, A. I. (2009). E-marketing (Vol. 4). São Paulo: Pearson Prentice Hall.Vernuccio, M. (2014). Communicating corporate brands through social media: An exploratory study. International Journal of Business Communication, 51(3), 211-233.öhttps://doi.org/10.1177/2329488414525400

Wang, A. (2007). Branding over mobile and Internet advertising: The cross-media effect. International Journal of Mobile Marketing, 2(1), 34-42.

Way, A. D., \& Austin, C. M. (2012). The epersona: Improving online communication, and developing friendships. Business Education Innovation Journal, 4(2), 58-65.

Publisher's Note: SSBFNET stays neutral with regard to jurisdictional claims in published maps and institutional affiliations.

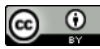

(C) 2021 by the authors. Licensee SSBFNET, Istanbul, Turkey. This article is an open access article distributed under the terms and conditions of the Creative Commons Attribution (CC BY) license (http://creativecommons.org/licenses/by/4.0/).

International Journal of Research in Business and Social Science (2147-4478) by SSBFNET is licensed under a Creative Commons Attribution 4.0 International License. 